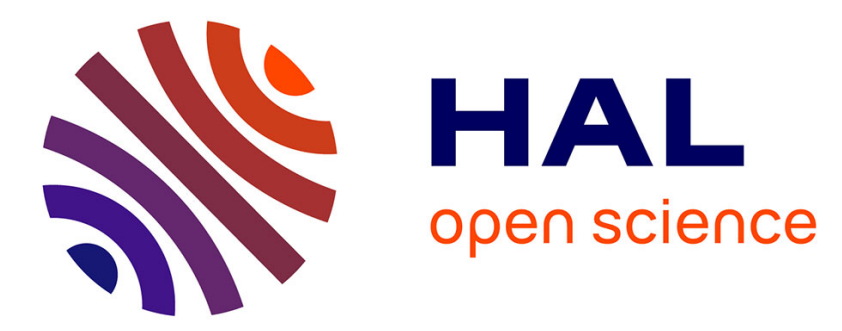

\title{
Room temperature hardness of carbides strengthened cast alloys in relation with their carbon content and aging temperature. Part 3 -Case of iron alloys
}

P. Berthod

\section{> To cite this version:}

P. Berthod. Room temperature hardness of carbides strengthened cast alloys in relation with their carbon content and aging temperature. Part 3 -Case of iron alloys. Materials Science and Technology, 2009, pp.1003 - 1008. 10.1179/174328409X430519 . hal-02433205

\section{HAL Id: hal-02433205 \\ https://hal.science/hal-02433205}

Submitted on 9 Jan 2020

HAL is a multi-disciplinary open access archive for the deposit and dissemination of scientific research documents, whether they are published or not. The documents may come from teaching and research institutions in France or abroad, or from public or private research centers.
L'archive ouverte pluridisciplinaire HAL, est destinée au dépôt et à la diffusion de documents scientifiques de niveau recherche, publiés ou non, émanant des établissements d'enseignement et de recherche français ou étrangers, des laboratoires publics ou privés. 


\title{
Room temperature hardness of carbides strengthened cast alloys in relation with their carbon content and aging temperature. Part 3 - Case of iron alloys
}

\section{P. Berthod*}

Laboratoire de Chimie du Solide Minéral (CNRS UMR 7555)

Faculté des Sciences et Techniques, Université Henri Poincaré Nancy 1, NancyUniversité,

Boulevard des Aiguillettes, BP 70239, F-54506 Vandoeuvre les Nancy, France

${ }^{*}$ Corresponding author, email: patrice.berthod@centraliens-lille.org

Post-print version of the article: Materials Science and Technology (2009) 25(8) 1003-1008.

DOI 10.1179/174328409X430519

\begin{abstract}
.
Vickers macro-indentation was performed on seven cast and aged $\{\mathrm{Fe}, 30 \mathrm{wt} . \% \mathrm{Cr}\}$-based alloys with carbon contents varying from 0 to $2.0 \mathrm{wt} . \%$. The measured hardness was studied versus the carbon content and the aging temperature (1000, 1100 and $\left.1200^{\circ} \mathrm{C}\right)$. The hardness increases with the carbon content, firstly slowly but much faster when the carbides fraction reaches 30 vol.\%. A hardness of $600 \mathrm{Hv}$ or more can then be achieved. For low carbon contents, the hardness increases slower than a law of mixture of the volume fractions and of the hardness of carbides and matrix. This is due to the great difference of hardness between the two phases responsible, which leads to the deformation of the matrix only. Beyond the critical value of 30 vol.\% of carbides, i.e. when the carbon content approaches $2 \mathrm{wt} \% \mathrm{C}$, hardness drastically increases since the main role in resistance against indentation is then played by the hard carbides skeleton which has become continuous enough.
\end{abstract}

Keywords: Iron alloy, Chromium carbides, Aging treatment, Vickers indentation, Macro and microhardness

\section{Introduction}


The hardness of carbon-containing iron-based alloys is generally of a great interest. It can considerably vary since very hard phases or components as pearlite, cementite or martensite can be present in the microstructures of $\mathrm{Fe}-\mathrm{C}$ alloys. These phases or compounds are favoured by a fast cooling after solidification (or from the austenitic domain) or by the presence of carbide-stabilizer or carbide-former elements in the chemical composition. Hardness measurement is usually used as a control mean of microstructure of cast iron ${ }^{1}$, but hardness can be also taken in consideration for other types of synthesis, e.g. rapidly solidified ${ }^{2}$ or even quenched Fe-based alloys ${ }^{3}$. When chromium is additionally present the hardness of bulk Fe-based alloys ${ }^{4}$ or of hardfacing deposits alloys ${ }^{5}$ can be significantly enhanced, for example by the formation of interdendritic chromium carbides in high quantities.

In this work, which follows two previous studies concerning the nickel-chromiumcarbon $^{6}$ and cobalt-chromium-carbon ${ }^{7}$ systems, several carbon-containing Fe-based alloys, all containing a high content of chromium (favourable to a good resistance against corrosion but also which is an important carbide-former element), were considered. They were elaborated by foundry and their Vickers hardness was measured and studied as a function of the carbon or carbide quantity, with also an attention given to the possible influence of the temperature at which the microstructure was stabilized during an aging treatment after casting. The knowledge of their room temperature hardness is potentially interesting to predict their wear resistance and the machining difficulty of such alloys that can be, for some of them, candidates as rigid structural materials, or alloys with reduced thermal expansion coefficients $^{8}$.

\section{Experimental}

\section{Elaboration of the alloys and preparation of the samples}

Seven alloys, all containing 30wt.\% of chromium, were elaborated by foundry from pure elements (iron and chromium Alfa Aesar, purity higher than 99.9wt.\% and graphite). Their names were defined from the targeted carbon contents: $\mathrm{Fe} 00$ (Fe-30Cr without $\mathrm{C}$ ), $\mathrm{Fe} 02$ (Fe30Cr-0.2C), Fe04 (Fe-30Cr-0.4C), and so on: Fe08, Fe12, Fe16 and Fe20 (with 2.0 wt.\%C).

Each charge (all of about 100g) was melted using a CELES high frequency induction furnace under an inert atmosphere (Argon U, 0.3 bar). Fusion and solidification were achieved in the same water-cooled copper crucible of the furnace. For each alloy, three parallelepiped parts (typically $10 \mathrm{~mm} \times 10 \mathrm{~mm} \times 3 \mathrm{~mm}$ ) were cut using a Buehler Isomet- 
5000 precision saw. Polishing was done using paper from 240 to 1200 grit. The three parts were then exposed at $1000^{\circ} \mathrm{C}, 1100^{\circ} \mathrm{C}$ or $1200^{\circ} \mathrm{C}$ in a tubular furnace for 50 hours in air, with finally a cooling at $10 \mathrm{~K} \mathrm{~min}^{-1}$ down to room temperature. Thereafter each part was cut and embedded in a resin + hardener mixture (Escil CY230 + HY956). The mounted samples were then polished with paper from 240 to 1200 grit and finished with $1 \mu \mathrm{m}$ alumina paste.

\section{Metallographic observations}

Each sample was etched using a Groesbeck solution (prepared with $4 \mathrm{~g}$ of $\mathrm{KMnO}_{4}$ and $4 \mathrm{~g}$ of $\mathrm{NaOH}$ in $100 \mathrm{~mL}$ of distilled water). Etching was done at room temperature during one minute. An Olympus optical microscope (model AH2) was used for the metallographic observation on etched samples, while micrographs were taken using an Olympus digital Camera (model DP11). Carbides were identified by their colour after etching, with confirmation by pinpoint Electron Probe Micro Analysis (EPMA) measurements using a Cameca SX100 microprobe.

Metallographic observations were completed by micrographs taken with a Scanning Electrons Microscope (SEM) used in Back Scattering Electrons (BSE) in order to get numeric micrographs more suitable for image analysis thanks to a better contrast between matrix and carbides. Image analysis was performed on three SEM/BSE micrographs for each alloy and each exposure temperature, by using the Adobe Photoshop CS software.

In order to better know what microstructures existed during the exposures at high temperature during the aging treatment, the Thermo-Calc software (Version N) was used for performing thermodynamic calculations, by exploiting a database in which the descriptions of the $\mathrm{Fe}-\mathrm{C}, \mathrm{Fe}-\mathrm{Cr}, \mathrm{C}-\mathrm{Cr}$ and $\mathrm{Fe}-\mathrm{Cr}-\mathrm{C}$ systems ${ }^{9-15}$ are present.

\section{Hardness measurements}

The hardness of all alloys after each aging treatment was measured, with two levels of load. Three 30kg-Vickers indentations were performed on each mounted sample, using a Testwell Wolpert apparatus. Five 8g-Vickers micro-hardness indentations were performed in the matrix of each sample, using a Reichert model D32 apparatus. In each case the average value and the standard deviation (uncertainty) were calculated. 


\section{Results}

\section{Description and quantification of the microstructures}

At room temperature, after cooling from the high temperature of aging treatments, the alloys are essentially composed of a dendritic matrix and of carbides, primary (interdendritic) and secondary in some cases (medium and high carbon alloys, mainly for $1000^{\circ} \mathrm{C}$ ). Thermo-Calc calculations show that carbides were $\mathrm{M}_{23} \mathrm{C}_{6}$ at high temperature while matrix is $\mathrm{BCC}$ for the five low carbon alloys (from $\mathrm{Fe} 00$ to $\mathrm{Fe} 12$ ), $\mathrm{BCC}+\mathrm{FCC}$ together for $\mathrm{Fe} 16$ and only $\mathrm{FCC}$ for Fe20. Thermo-Calc indicates that FCC would disappear for lower temperatures (e.g. the matrix of $\mathrm{Fe} 20$ is $\mathrm{BCC}$ for $800^{\circ} \mathrm{C}$, according to the thermodynamic equilibrium) and then tends to disappear during cooling, while the $\mathrm{M}_{23} \mathrm{C}_{6}$ stays until room temperature. Calculations also predict a possible appearance of the $\mathrm{FeCr}$ sigma phase.

After Groesbeck etching, the $\mathrm{M}_{23} \mathrm{C}_{6}$ carbides appear with a blue colour, with a more pale/white coloration (generally after exposure at $1200^{\circ} \mathrm{C}$, or on the contrary a little darker (after exposure at $1000^{\circ} \mathrm{C}$ ), this depending on the carbon content and on the aging treatment. More precisely, when the temperature of the aging treatment was high enough to favour a coarsening of the carbides, the obtained blocky carbides were blue and clear. It is in these cases that the carbides size allowed EPMA analysis which clearly showed the $\mathrm{M}_{23} \mathrm{C}_{6}$ stoichiometry. On the contrary, after aging treatment at $1000^{\circ} \mathrm{C}$ the carbides are too elongated to clearly display the blue colour and then they appear darker, even for Fe20. In addition they are also more difficult to analyze by EPMA. These microstructures are illustrated by examples given in Fig. 1 for three carbon contents covering the studied range [0 to $2 \mathrm{wt} . \%$ ] and for the two extreme temperatures of aging.

Because of the varying clearness of the carbides after etching, it was preferred to measure the surface fractions on SEM micrographs in BSE mode, on which all carbides (gray) are clearly distinguished from matrix (white). The results for all the alloys and for the three aging temperatures are plotted in Fig. 2 as a function of the carbon content. The increase in carbide surface fraction with the carbon content is evident for the three aging treatments, and it can be underlined that very high carbides fractions can be achieved (30 vol.\% or more) with only 2 wt.\% C. It can be noted that, for all alloys, the fraction of carbides slightly decreases when the temperature of aging treatment increases. One can also notice that the $\mathrm{Fe} 02$ alloy also contains a small fraction of carbides but it was too difficult to measure them with a sufficient precision. 


\section{Vickers micro- and macro-indentation}

Micro-indentation measurements, with a load of $8 \mathrm{~g}$, were performed in the matrix of each sample. It appears that the micro-hardness of the matrix clearly depends neither on the alloy, nor on the aging temperature. The variations mainly remain in the 150-180 range, without systematic relationship with the carbon content in alloy and the aging temperature. However, some values measured in the small domains of matrix sometimes reached high values (about $500 \mathrm{Hv} 8 \mathrm{~g}$ in Fe16 and Fe20) but this was probably due to the neighbourhood of the dense carbides skeleton.

On the contrary, the macro-hardness of alloys for a load of 30kg clearly depends on the carbon content in the alloy, as it can be seen in Fig. 3. From the binary Fe00 alloy up to the Fe16 alloy, the hardness continuously increases with the carbon content. Thereafter it suddenly increases to reach more than $600 \mathrm{Hv} 30 \mathrm{~kg}$ with the Fe20 alloy. The slow, and seemingly almost linear $(\mathrm{Fe} 00 \rightarrow \mathrm{Fe} 12 / \mathrm{Fe} 16)$ increase in hardness, followed by a quick (Fe16 $\rightarrow$ Fe20) jump, can also be observed when the plot is done versus the surface carbide fraction measured by image analysis (Fig. 4). The hardness also depends a little on the aging treatment since the hardness slightly decreases when the aging temperature increases, for some of the alloys.

Since the hardness increases almost linearly with the surface fraction (supposed to be also the volume fraction) of carbides before reaching $1.6 \mathrm{wt} . \% \mathrm{C}$, it can be thought that the hardness of the alloy may be a linear combination of the volume fractions of matrix and carbides, each multiplied by its specific hardness. Thus, for each temperature of aging treatment, Fig. 5 displays together, firstly the curve of variation of the average hardness of the alloy versus the carbon content ("meas."), and secondly a theoretic curve ("theo.") representing, versus the carbon content too, the following quantity:

$\mathrm{Hv}(\mathrm{all})=(1-\mathrm{fvol}(\mathrm{carb})) \times \mathrm{Hv}(\mathrm{mat})+\mathrm{fvol}(\mathrm{carb}) \times \mathrm{Hv}(\mathrm{carb})$

where:

* $\mathrm{Hv}$ (all) is the average Vickers hardness Hv30kg of the whole alloy,

* fvol(carb) is the average value of measured surface fraction of carbides

* $\mathrm{Hv}(\mathrm{carb})=1650$, hardness of the $\mathrm{Cr}_{23} \mathrm{C}_{6}$ carbide ${ }^{16}$

* $\mathrm{Hv}$ (mat) is the average value of the Hv30kg hardness obtained on the binary alloy Fe00 (Fe-30wt.\%Cr, 174 Hv30kg). 
The slope of the theoretic curve is significantly higher than the one of the experimental curve between $\mathrm{Fe} 00$ and $\mathrm{Fe} 16$, and, for the first half of the carbon content range, the fit is good only for the alloy with the lowest carbon contents. For medium carbon contents, the mismatch is very high, and it decreases for a new good correspondence for Fe20 only.

\section{Discussion}

The microstructures of these $\mathrm{Fe}-30 \mathrm{Cr}-\mathrm{xC}$ alloys showed that the $[0 ; 2$ wt.\%] range of carbon content obviously led to an especially wide range of volume fractions of carbides. This consequently led here to the possibility of obtaining high values of hardness at room temperature. When a $\{\mathrm{Fe}-30 \%$ wt.Cr $\}-$ based alloy becomes more and more rich in carbon, its hardness increases from its initial low value (about $170 \mathrm{Hv}$ ), with an average slope which is, between $0 \mathrm{wt} . \% \mathrm{C}$ and $1.6 \mathrm{wt} . \% \mathrm{C}\left(1.2 \mathrm{wt} . \% \mathrm{C}\right.$ for $\left.1,200^{\circ} \mathrm{C}\right)$, of about $107 \mathrm{Hv} 30 \mathrm{~kg} \% \mathrm{wt} . \mathrm{C}^{-1}$ for an aging done at $1000^{\circ} \mathrm{C}, 60 \mathrm{Hv} 30 \mathrm{~kg} \% \mathrm{wt} . \mathrm{C}^{-1}$ for $1100^{\circ} \mathrm{C}$ and $38 \mathrm{Hv} 30 \mathrm{~kg} \% \mathrm{wt}^{-1}$ for $1200^{\circ} \mathrm{C}$. These rates are significantly lower than the ones which can be calculated by the law of mixture (respectively 320,308 and $271 \mathrm{Hv} 30 \mathrm{~kg} \% \mathrm{wt}^{-\mathrm{C}^{-1}}$ for the same carbon ranges). The ratios (theo. / meas.) between the too are $\times 3$ for $1000^{\circ} \mathrm{C} \times 5$ for $1100^{\circ} \mathrm{C}$ and $\times 7$ for $1200^{\circ} \mathrm{C}$.

This mismatch, which can also be encountered for carbides-containing nickel alloys ${ }^{6}$, is probably due to the great difference of hardness between the matrix and the chromium carbides, which involves a plastic deformation of the matrix only. However, there is a little participation of the carbides to the hardness, despite their low volume fraction for these lowcarbon alloys, since one can note a slow but existing increase in hardness when the carbon content increases. This is more significant for an aging treatment performed at $1000^{\circ} \mathrm{C}$ than for an aging done at $1200^{\circ} \mathrm{C}$, because of the modification of the carbides network occurring at $1200^{\circ} \mathrm{C}$. Indeed this led to blockier and less interconnected carbides which then less participate to the resistance against plastic deformation, and let matrix exposed to the whole plastic deformation.

In the case of the Fe20 alloy, the volume fraction of carbides is high enough (more than $30 \mathrm{vol} . \%$ ), and then interconnected enough to allow the carbide network taking a real part in the resistance against the penetration of the indentor, with consequently the strong increase in alloy hardness occurring with Fe20. This value of 30 vol.\% appears characterizing the continuity of the carbides network, not only about simple geometric interconnection but also in the point of view of efficiency of the resistance against indentation. This value of 
carbide fraction can be considered as critical since it marks a transition from a plastic deformation concerning essentially the matrix, to another type of deformation, plastic again (but less severe) for matrix and simultaneously elastic (with partly ruptures) for carbides. From this critical carbide fraction, the hardness is significantly increased. For $2 \mathrm{wt} . \% \mathrm{C}$ hardness seems join again the hardness given by the law of mixture but this is probably a pure coincidence: one can think that, for a carbon content increasing beyond $2 \mathrm{wt} . \% \mathrm{C}$, the real hardness should go on increasing faster than the law of mixture since the carbide network should be then the new principal acting phase, in contrast to the case of the lowest carbon contents for which it was the matrix which was principally concerned by deformation. This must be verified later by a new study concerning alloys with carbon contents higher than $2 \mathrm{wt} . \%$.

It can be also interesting to graphically compare the alloys of this study with nickelbased $^{6}$ and cobalt-based ${ }^{7}$ similar alloys with the same chromium and carbon contents, for example by plotting hardness versus either the carbon content, or carbides fraction, for the three families together (Fig. 6). One can find again that the hardness of the cobalt alloys (which well follows its law of mixture ${ }^{7}$ ) is always higher than the hardness of the nickel alloys for the same carbon contents or carbides fraction, thanks to the higher intrinsic hardness of the cobalt matrix. The iron alloys, despite their carbide fraction which increases more rapidly with carbon than in the nickel alloys and the cobalt alloys, globally follows the same increase in hardness as the nickel alloys, but only until the famous sudden jump in hardness near $2 \mathrm{wt} . \% \mathrm{C}$ which allows the iron alloys becoming harder than the cobalt ones.

To finish, some comments can be done also about the possible use of such iron alloys for applications at high temperature (i.e. $1000^{\circ} \mathrm{C}$ and more). First, on the one hand, with $30 \mathrm{wt} . \% \mathrm{Cr}$ these alloys are able to resist hot corrosion, and on the other hand, one can remember that it was previously observed that $\{\mathrm{Fe}-30 \mathrm{wt} . \% \mathrm{Cr}\}$-based alloys ${ }^{17}$ are nearly as refractory as the corresponding Ni-based alloys ${ }^{18}$ and Co-based alloys ${ }^{19}$, with solidus temperatures at least of about $1300^{\circ} \mathrm{C}$ even for high carbon contents. Second, it has been observed here that the chromium carbides obtained in the $\mathrm{Fe}-30 \mathrm{wt} . \% \mathrm{Cr}$ base can be significantly more numerous and/or coarse than in the similar Ni-based or Co-based alloys for the same contents in carbon. This leads to surface or volume fractions that are very high, for example almost 10 vol.\% more for Fe20 than for a Ni-30Cr-2.0C and a Co-30Cr-2.0C alloy after the same aging treatment, with probably an enhanced mechanical strength at high temperature which comes completing the set of properties required for uses at high temperature. 


\section{Conclusion}

The hardness of corrosion-resistant $\{\mathrm{Fe}-30 \mathrm{Cr}\}$-based alloys can be enhanced by the presence and the increasing density of chromium carbides (with inversely a more difficult machinability). These Fe-based alloys can reach higher volume fractions of carbides than other types of alloys for the same carbon content (based on $\mathrm{Ni}$ or $\mathrm{Co}$ ). The increase in hardness with carbon is neither totally linear, nor conform to a law of mixture, because of both the great difference of intrinsic hardness between matrix and carbides (i.e. as already met with nickel alloys ${ }^{6}$ ), and an inversion of the roles of the two phases when the carbon content is become high enough. Near $2 \mathrm{wt} . \% \mathrm{C}$, i.e. 30vol.\% of carbides, the carbides are seemingly sufficiently interconnected to allow the rigid skeleton that they compose, taking the main part of the resistance against indentation. Hardness may probably go on increasing for carbon contents higher again, this permitting to think that this ternary system is able to offer alloys which are simultaneously corrosion-resistant, very hard and even refractory, despite they can be easily synthesized (by foundry).

\section{Acknowledgement}

The author gratefully thanks Pierric Lemoine who elaborated and heat treated some of the studied alloys.

\section{References}

[1] E.F. Ryntz and H.L. Arnson: Modern Casting, 1976, 66, 53-54.

[2] K. Kishitake, H. Era and F. Otsubo: Script. Met. Mater., 1990, 24, 1269-1273.

[3] A. Litwinchick, F.X. Kayser, H.H. Baker and A. Henkin: J. Mater. Sci., 1976, 11, $1200-1206$.

[4] H.E.N. Stone: J. Mater. Sci., 1979, 14, 2781-2786.

[5] B.V. Cockeram: Met. Mater. Trans. A: Phys. Met. Mater. Sci., 2002, 33, 3403-3419.

[6] P. Berthod, Mat. Sci. Technol., in press.

[7] P. Berthod, Mat. Sci. Technol., in press.

[8] P. Berthod: Int. J. Mat. Res. (formerly Z. Metallkd.), 2008, 99, 265-272.

[9] A. Fernandez Guillermet and P. Gustafson: High Temp. High Press., 1984, 16, 591610.

[10] J.-O. Andersson: Int. J. Thermophys., 1985, 6, 411-419.

[11] P. Gustafson: Carbon, 1986, 24, 169-176. 
[12] J.-O. Andersson, and B. Sundman: Calphad, 1987, 11, 83-92.

[13] P. Gustafson: Scan. J. Metall., 1985, 14, 259-267.

[14] J.-O. Andersson: Calphad, 1987, 11, 271-276.

[15] J.-O. Andersson: Met. Trans. A, 1988, 19A, 627-636.

[16] G.V. Samsonov: 'High-Temperature. Materials Properties Index'; 1964, New York, Plenum Press.

[17] P. Berthod, P. Lemoine and J. Ravaux: Int. J. Mat. Res. (formerly Z. Metallkd.), 2008, 99, 964-972.

[18] P. Berthod, P. Lemoine, L. Aranda: Calphad, 2008, 32, 485-491.

[19] P. Berthod, P. Lemoine and J. Ravaux: J. Alloys Compd., 2009, 467, 227-234. 


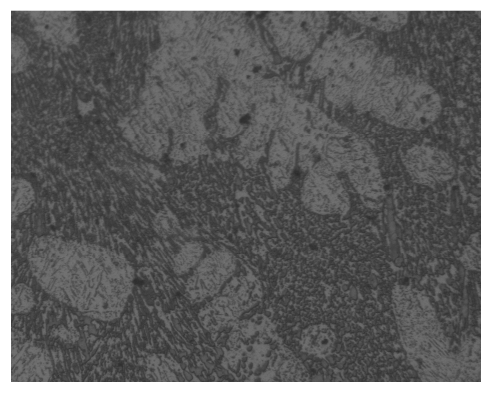

Scale for all micrographs:
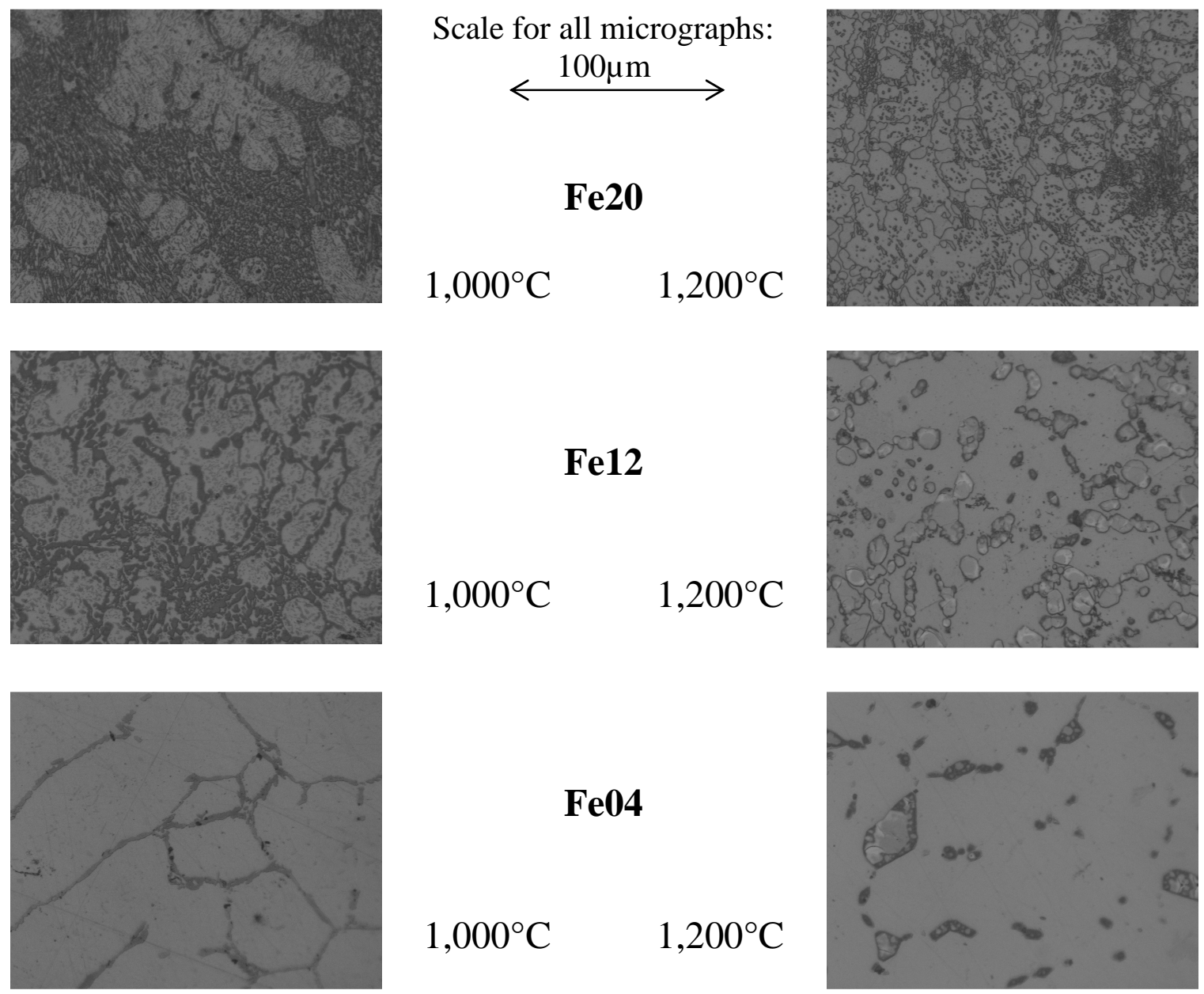

Fig. 1 Microstructures of selected Fe-base carbon-containing alloys after aging at $1,000^{\circ} \mathrm{C}$ and $1,200{ }^{\circ} \mathrm{C}$ for 50 hours (after 1 minute of etching in Groesbeck solution) 


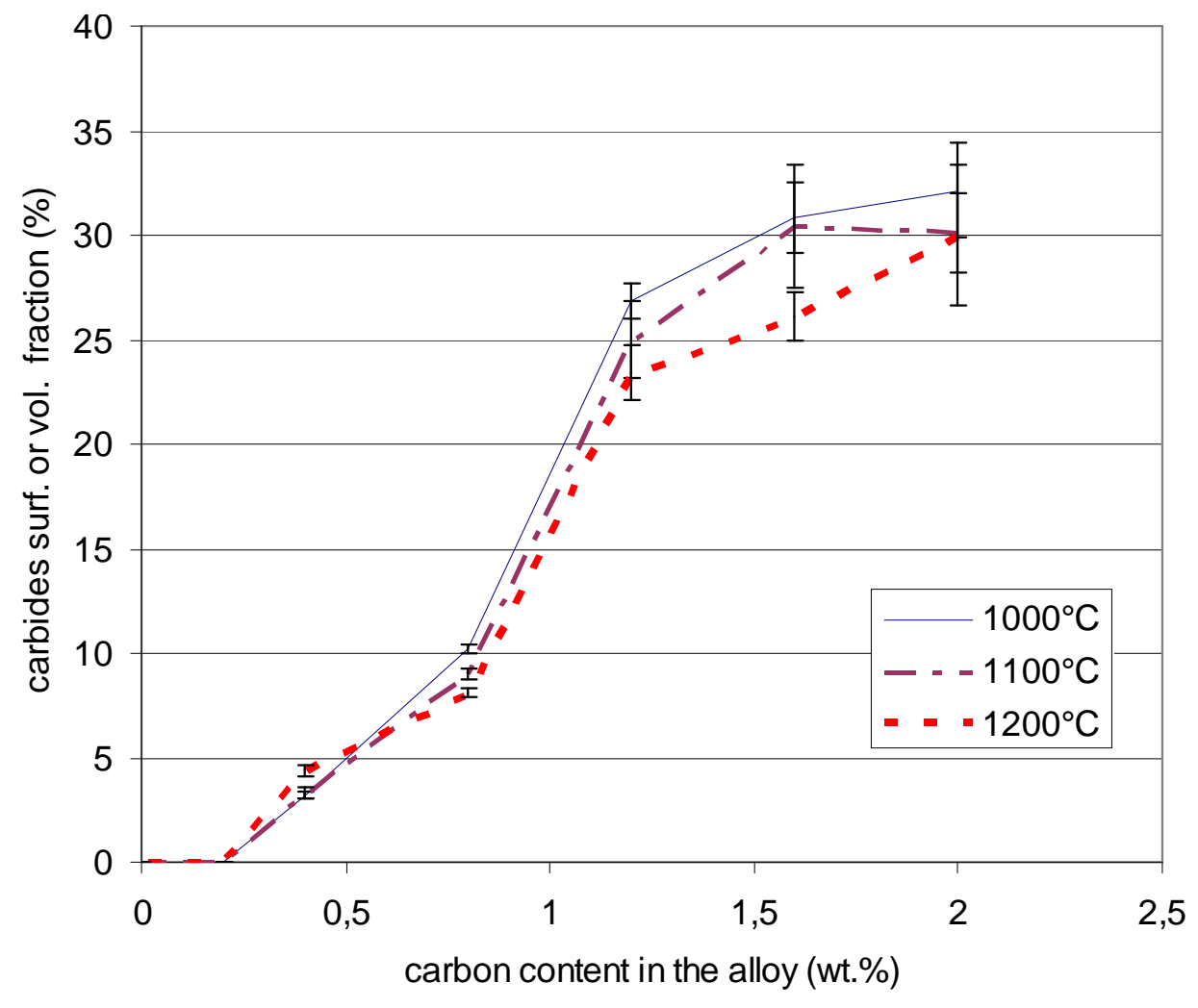

Fig. 2 Surface fractions of carbides plotted versus the carbon content of alloy for the three aging temperatures (determination by image analysis on three SEM micrographs taken in BSE mode; average value \pm standard deviation) 


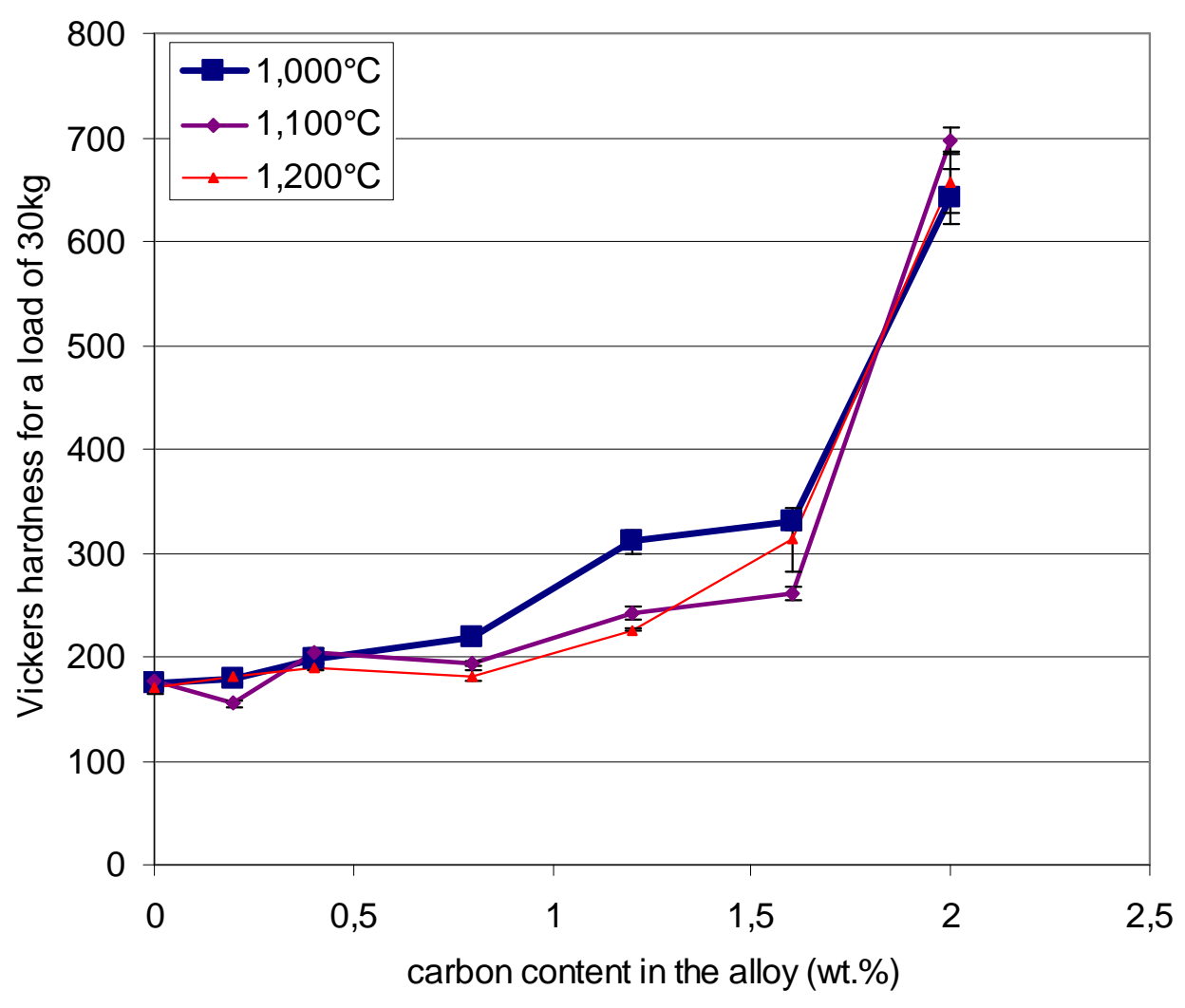

Fig. 3 Vickers hardness (30kg) plotted versus the alloy's carbon content for the three aging temperatures (average value \pm standard deviation) 


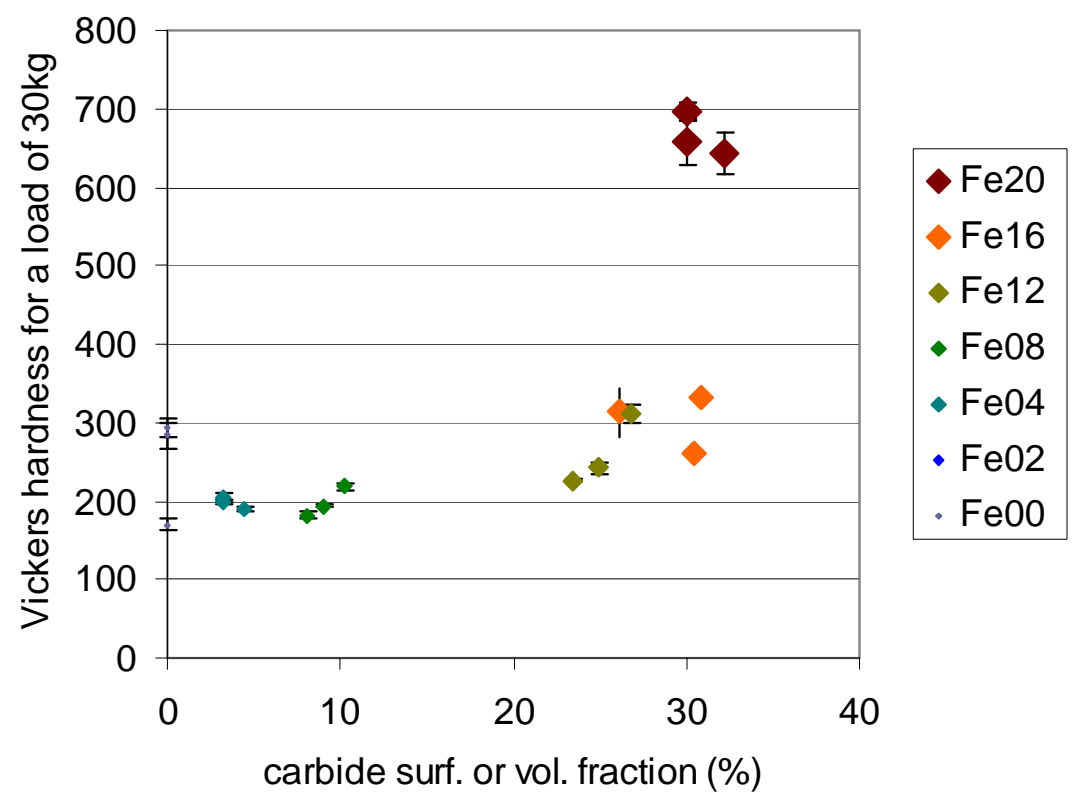

Fig. 4 Vickers hardness (30kg) plotted versus the alloy's carbide fraction (all aging temperatures together) 

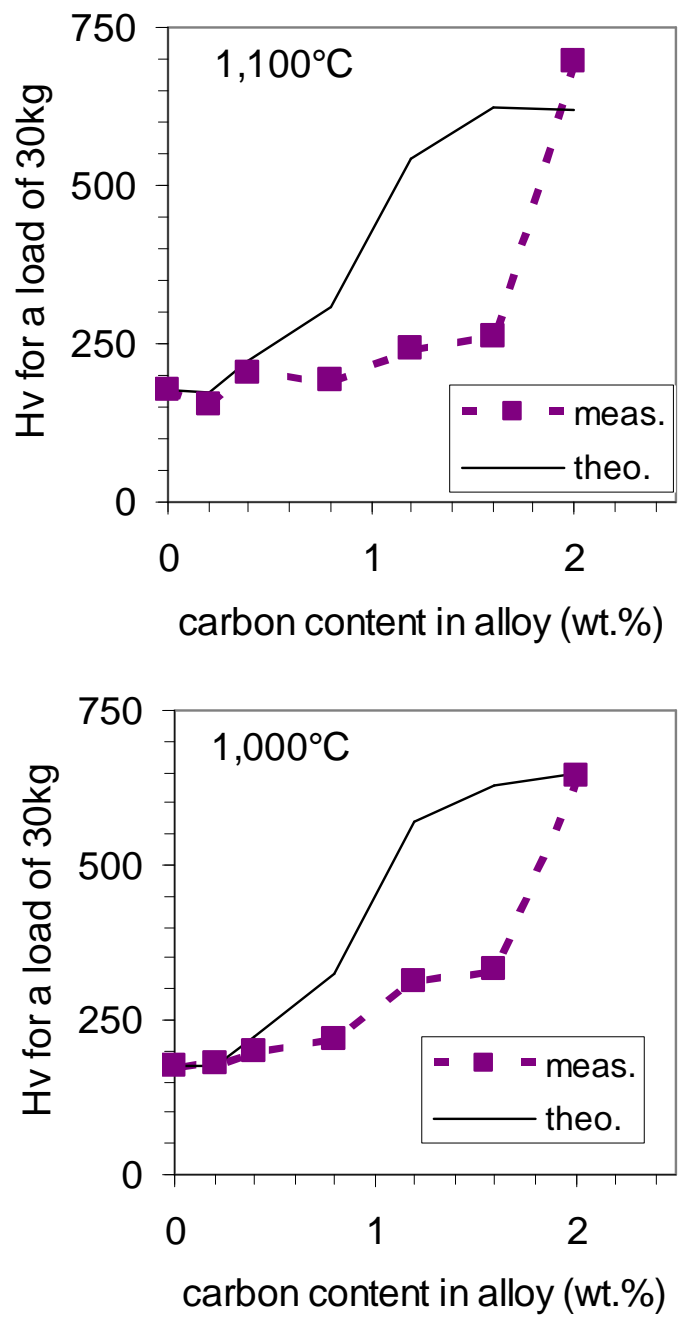

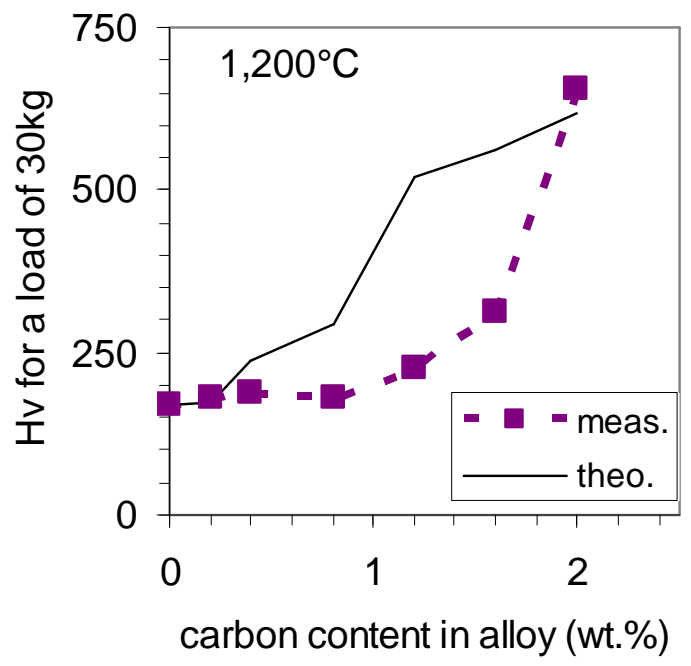

Fig. 5

Comparison of the measured hardness with the theoretic hardness calculated from the hardness of matrix and the hardness of $\mathrm{Cr}_{23} \mathrm{C}_{6}$ carbides ${ }^{14}$ 

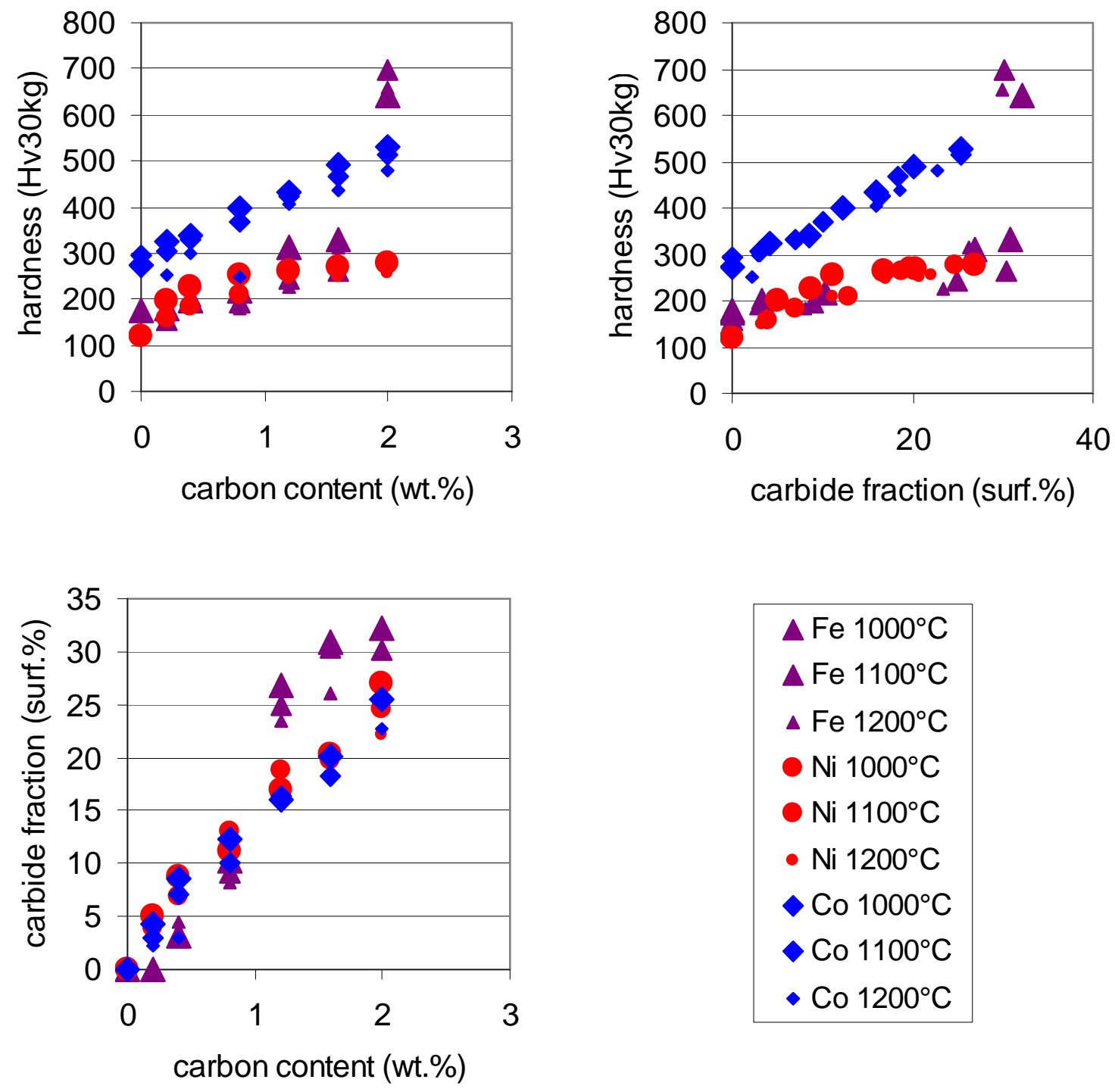
$\Delta \mathrm{Fe} 1000^{\circ} \mathrm{C}$
$\triangle \mathrm{Fe} 1100^{\circ} \mathrm{C}$
$\triangle \mathrm{Fe} 1200^{\circ} \mathrm{C}$
- Ni $1000^{\circ} \mathrm{C}$
- Ni $1100^{\circ} \mathrm{C}$
- Ni $1200^{\circ} \mathrm{C}$
$\rightarrow \mathrm{Co} 1000^{\circ} \mathrm{C}$
$\rightarrow \mathrm{Co} 1100^{\circ} \mathrm{C}$
- Co $1200^{\circ} \mathrm{C}$

Fig. 6 Comparison of the results obtained for the $\{\mathrm{Fe}-30 \mathrm{wt} . \% \mathrm{Cr}-0$ to $2 \mathrm{wt} . \% \mathrm{C}\}$ alloys of this study with the results previously obtained for the corresponding Ni-based alloys ${ }^{6}$ and Cobased alloys $^{7}$ (average values only) 